\title{
De espectador a militante: los hinchas del fútbol y su lucha por el derecho al estadio y al club
}

Irlan Simões Santos iirlansimoes@gmail.com

Universidade Estadual do Rio de Janeiro
Ronaldo George Hela rhelal@globo.com

Universidade Estadual do

Rio de Janeiro

Cómo citar este artículo:

Santos, I. \& Hela, R. (2019). De espectador a militante: Ios hinchas del fútbol y su lucha por el derecho al estadio y al club (Traductor Londoño-Matta, J.).Trans-Pasando Fronteras, (13). doi: 10.18046/retf.i13.3493

1 Nota del editor: traducción de Jaime E. Londoño M. Orcid https://orcid.org/00000002-2128-727X Revisión final Jaime Amparo Alvez. Título original "Do espectador ao militante: a torcida de futebol e a luta pelo direito ao estádio e ao clube", en. Tríade: comunicação, cultura e mídia. 4 (7), 53-69. Agradecemos a los colegas Irlan Simões Santos y Ronaldo George Hela por conceder el permiso para la traducción y publicación de este artículo- Asimismo a la revista Tríade: comunicação, cultura e mídia por su consentimiento. 


\section{Resumen}

El artículo reflexiona sobre el origen de varias experiencias organizativas de hinchas en Brasil en los últimos años, creadas con el fin de canalizar sus intereses en torno al fútbol. Las agendas de estas organizaciones se pueden resumir en dos temas principales: el derecho al estadio y el derecho al club, que aquí se entenderán como bienes comunes amenazados por la lógica privatizadora y excluyente de la ciudad neoliberal de hoy. Con este fin, se hará una breve historia de la formación del fútbol, los estadios y la cultura de los hinchas; posteriormente, se discutirán los movimientos de los hinchas en el mundo y en Brasil.

\section{Introducción}

Desde el segundo quinquenio de la década de 2000, se han identificado experiencias organizativas de hinchas brasileños con el propósito de establecer derechos democráticos de acceso a los estadios y a sus clubes. Estas experiencias se han ampliado considerablemente desde la realización del Mundial de Fútbol de 2014. A lo largo de este artículo argumentamos que estas experiencias no son exclusivas de Brasil, trataremos de entenderlas a partir del análisis de los cambios ocurridos en la estructura capitalista de las ciudades y cultura y cómo tienen un impacto directo en el fútbol.

Con la pretensión de situar estas experiencias, como organizaciones de la sociedad civil", con directrices establecidas, las denominaremos "movimientos de hinchas. Si bien algunas de estas agrupaciones se reivindican como un "movimiento social", otras optan por utilizar el nombre de "grupo" o "frente", configurando diferentes perfiles y métodos de acción, táctica y estratégica política. Las agendas de estas 
organizaciones se pueden agrupar en dos problemáticas fundamentales: el derecho al estadio y el derecho al club.

En lo que concierne al derecho al club, se ha identificado el surgimiento de movimientos de hinchas comunes, quienes demandan una mayor participación política, tanto a partir de la presión ejercida sobre los dirigentes como de forma organizada a través de exigencias de redefinición de los estatutos sociales de estas instituciones, para hacerlas más accesibles y democráticas. Estos grupos se diferencian de antiguas experiencias, al no estar directamente relacionados con ninguna fuerza política ni con las familias tradicionales que conformaban los consejos directivos de estas instituciones. En lo que respecta al derecho al estadio, se plantean diferentes reivindicaciones: 1) La democratización de la entrada a los partidos e impugnan el precio elevado de la boletería; 2) el levantamiento de las disposiciones que restringen las manifestaciones festivas en las tribunas, la prohibición de banderas, los artefactos pirotécnicos, las bebidas alcohólicas y el derecho a ver el partido en pie; y 3) reclamaciones referentes al formato (modelo) del espacio físico del estadio; además de los horarios de los partidos.

En este sentido, este es un estudio sobre los hinchas (fans, aficionados, supporters, tifosi) inmersos en una política identitaria y de afinidad con sus clubes [equipos], quienes rechazan los discursos que asocian el "fútbol a un negocio" y se oponen a directrices, que, si bien favorecen las finanzas del club, pueden ser contraproducentes para el resto de la hinchada². Para una mayor compren-

${ }^{2}$ Critcher (1979) desarrolló una taxonomía de las identidades de los hinchas en el fútbol inglés, los definió como "miembros", clasificación mejorada y actualizada por Giulianotti (2012), quien los definió como "fanáticos". Al respecto, véase Santos (2015b). 
sión de esta posición beligerante, analizaremos aspectos de la formación histórica del fútbol, el estadio y los hinchas.

\section{Ciudad, capitalismo industrial, trabajo y tiempo libre}

Los cuatro conceptos del subtítulo tienen una relación tan directa con la historia del fútbol, que si no son tenidos en cuenta es casi imposible la comprensión de esta práctica cultural. Para eso es necesario retroceder a los finales del siglo XVIII, a la época de consolidación del capitalismo industrial en Inglaterra. En este entonces, el alto flujo de población que se desplazaba hacia las zonas urbanas era un grave problema para las clases dominantes, como también lo era la necesidad de "reeducar" a los nuevos trabajadores asalariados. En contraposición a la lógica de trabajo hasta entonces "orientada a las tareas", se mejoró la fijación del tiempo con el reloj, campanas y sirenas. El resultado de eso fue la homogenización del tiempo y el aumento de la carga laboral hasta horas 16 al día.

La ética protestante - que combinaba la lógica doble de un discurso religioso radical y punitivo con un ethos típicamente burgués del cuerpo para la producción de riqueza, restringiendo el tiempo al máximo de la racionalidad - sería ahora el bastión de la formación de esta nueva sociedad, que experimentaría largos años de conflicto, resistencia y divergencias. Después de todo, el problema no se reducía únicamente al rechazo de la gran mayoría de los trabajadores a las normas impuestas, sino también a las formas en que utilizaban su tiempo fuera de la fábrica. En términos más precisos: ¿qué pasó con el "tiempo libre" de estos trabajadores? Thompson (1998, p. 295) demostró como la sociedad de entonces disciplinaba, consumía y negociaba el tiempo. De lo contrario, se consideraría improductivo e inapropiado. 
A partir de la tercera década del siglo XIX se configuró la época victoriana, con ella se fortaleció y mejoró el marco de normalización moralista y disciplinaria; que a su vez, refinó las tecnologías sociales de control, fundamentalmente, la educación cívica. El nexo de la nueva moral burguesa con los preceptos religiosos explica los ataques iniciados contra las costumbres, juegos y fiestas populares de la época. Algunos documentos reseñan la clasificación de los sujetos que participaban de las actividades de ocio en las calles: disoluto, depravado, bruto, insolente, libertino, extravagante, ocioso, carente de religión, blasfemo, entre otros (THOMPSON, 1998, p. 308).

Es justamente en la época victoriana cuando algunas de estas actividades de ocio, especialmente los juegos colectivos, serán apropiados e incorporados a la educación de los jóvenes ricos de las escuelas inglesas; en estas instituciones, se perfeccionarán e integraran con aquellos aspectos que representaban los valores predominantes de la época - disciplina, obediencia y competitividad-y los valores típicos del hombre burgués. En este contexto nace en cercanías de Londres, la Footbal association en 1863, reunión de doce clubes, que bajo principios comunes empezaron un proceso de definición y estandarización de las reglas del fútbol (SANTOS, 2014). A manera de contexto, la fundación de la primera asociación tuvo lugar cuatro años después del lanzamiento de dos obras históricas (Contribuciones a la Crítica de la Economía Política de Karl Marx y El Origen de las Especies de Charles Darwin) del pensamiento europeo.

Casi veinte años después, más de mil clubes de fútbol estaban registrados en toda Inglaterra, cifra que revelaba la consolidación de la difusión de este deporte, incluso antes de su estandarización. El fútbol nació durante la segunda revolución industrial, que mejoró y 
perfeccionó las tecnologías de la primera, acelerando la producción y transporte de mercancías. La difusión mundial de los componentes culturales ingleses, entre ellos el deporte, fue favorecido por la expansión imperialista del capitalismo industrial inglés. En este contexto el fútbol adquirió un protagonismo especial.

En una reunión de un grupo de aristócratas europeos en 1890, bajo el mando del Barón de Coubertin, se determinó reanudar los Juegos Olímpicos de la Antigua Grecia (siglo XVIII a.C) - al menos lo que se idealizaba de esos acontecimientos-. Lógicamente, esta vez, resaltando los valores requeridos por la ética del mundo burgués, como la competitividad, el mérito y la disciplina, dejando de lado o haciendo caso omiso de valores menos "civilizados" para los estándares de la sociedad moderna, como la tolerancia a la violencia física.

En este contexto se pueden identificar dos procesos desiguales pero relacionados: la expansión de una práctica "oficial" de jugar al fútbol, representada por torneos de clubes aficionados constituidos por comunidades locales; y la conformación de un "público" reunido en torno a los lugares donde se jugaba este fútbol. Este fue el embrión de lo que hoy conocemos como hinchadas. Jugar e hinchar se conjugaron mutuamente en el devenir del fútbol.

Estas características fueron centrales en la expansión mundial del fútbol. Sin embargo, hay que tener en consideración las particularidades de casos específicos como el de Brasil, donde el fútbol, por ejemplo, fue introducido por jóvenes de la alta sociedad que regresaban después de sus estancias de estudio en Inglaterra. Su práctica "oficial", era considerada símbolo de distinción social por una elite moderna entusiasta con el cuerpo. Por los objetivos del artículo y el poco espacio para el desarrollo de estas temáticas, nos limitaremos a trazar elementos similares en el desarrollo del fútbol. 


\section{Fútbol entre el Estado y la Capital: pensando en el estadio}

En este periodo, la transformación del "fútbol oficial" (favorecido en términos dialécticos por la continuidad del "fútbol popular" jugado fuera de los circuitos relacionados con clubes y asociaciones), en una práctica popular de grandes dimensiones y adquirir la estructura necesaria y adecuada para convertirse en una mercancía, representó las fases iniciales de una de las industrias culturales más poderosas e influyentes del siglo XX.

Con el creciente interés del público por los partidos, se crearon las diferencias espaciales definitivas entre el terreno de

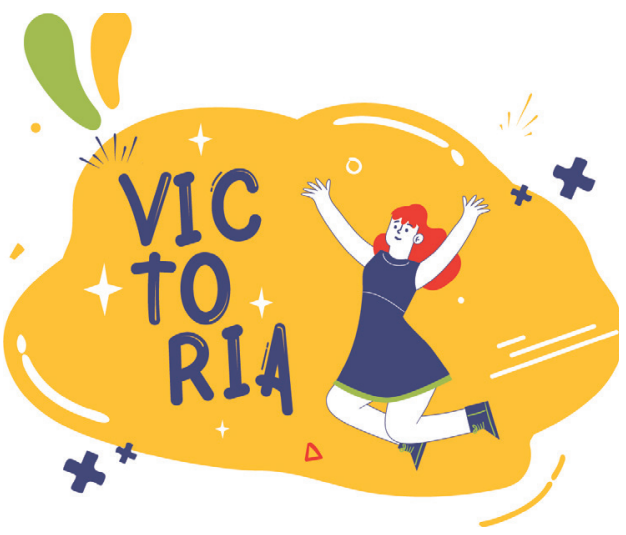

"Jugar e hinchar se conjugaron mutuamente en el devenir del fútbol." juego (cancha) y el espacio de las hinchadas (graderías)3. El uso de cuerdas y de rejas para distanciar el púbico del campo de juego se hizo pensando en el lugar que lo albergaría: las tribunas y graderías de los escenarios deportivos.

\footnotetext{
3 Henrique S. Santos (2012), reseña registros periodísticos que atribuyen el cobro de entradas de fútbol en Salvador en 1907.
} 
En 1874, el Aston Villa, ya cobraba al público asistente por acceder a las graderías. Una cultura de hinchas más ligada a la clase obrera surgirá en este contexto, cuando las entradas más baratas permitieron su ubicación detrás de la portería, zona conocida popularmente como terrazas, donde no había asientos, sólo escombros y montones de tierra (CRUZ, 2005).

La profesionalización de la práctica del fútbol no tardaría mucho en acontecer, ya que los jugadores más destacados necesitaban complementar los ingresos familiares con otras actividades. La búsqueda de suplir los trabajos agotadores o la ausencia de este, hizo que los clubes de los barrios y comunidades buscaron, a través de contribuciones y ventas de entradas para las tribunas de los estadios, la manera de financiarse para retener sus filas a los buenos jugadores ${ }^{4}$.

Critcher(1979) puntualizó que de esta forma los valores esenciales del deporte profesional, como masculinidad, agresividad, empatía física, victoria e identidad regional, se fusionaron con la cultura de la clase obrera, mayoritariamente masculina. Se refiere a las organizaciones y a los mecanismos de solidaridad entre los trabajadores, como clubes, sistemas de seguridad, cooperativas, albergues, sindicatos y variados lugares de ocio, que congregaba a criadores de palomas, adiestradores de perros, futbolistas aficionados y muchos otros.

Estos elementos dan pistas para explicar la normatividad sexista de los estadios, que perdura hasta la actualidad. El fútbol se configuró en un momento en que la ideología dominante predicaba -y el sentido común rectificaba- que las mujeres eran seres

\footnotetext{
${ }^{4}$ En Inglaterra, la solicitud de profesionalización ocurrió en 1885. En Brasil, último bastión de la resistencia del deporte amateur no ocurrió este cambio sino hasta 1933.
} 
inferiores, biológica y mentalmente incapaces de realizar ciertas actividades. A su vez, la formación de la cultura popular de las hinchadas surgió en el contexto de apropiación de los estadios por parte de una clase obrera masculinizada, que poco a poco ganó el derecho al tiempo libre, con la reducción de la jornada laboral. Estas conquistas se traducirían en la consigna "8 horas de trabajo, 8 horas de descanso, 8 horas de ocio". Aunque muchas mujeres, desde muy jóvenes, eran trabajadoras remuneradas, a diferencia de los hombres, no tenían derecho a "tiempo libre" gratuito o remunerado para dedicarlo al ocio. El lugar de la mujer fuera de la fábrica estaba reservado para el trabajo reproductivo, en el ámbito doméstico. El tiempo libre estaba dividido social y sexualmente como trabajo en sí mismo ${ }^{5}$.

Desde la perspectiva de la cuestión racial, (un aspecto sobresaliente en Brasil ya que las migraciones de las colonias americanas y africanas a Inglaterra sólo se producirían a mediados del siglo $X X)$, el fútbol afrontó varias tentativas de segregación. No es raro que los estatutos de fundación de muchos clubes prohibieran categórica y explícitamente la participación de negros, pardos y trabajadores manuales. Estos impedimentos generaron divisiones en varias federaciones estatales, con muchos clubes fundados posteriormente por miembros de sectores populares.

Con la admisión de negros y pardos en los clubes más ricos del país, estas tensiones disminuyeron. Ahora ellas se reflejaron en la estructura física de los estadios, que se pensaban, literalmente, de

5 En los primeros tiempos entre los espectadores del fútbol y otros deportes, la presencia de mujeres de las clases más acomodadas era muy común e incluso elogiada. En los tiempos aristocráticos del "fútbol profesional", la asistencia a los estadios era un símbolo de distinción. 
manera clasista: sectores especiales y más costosos para la elite económica y política, graderías para la burguesía, y amplios sectores sin asientos, incluso sin gradas de cemento, pesimamente ubicados y con ángulos de observación deficientes respecto al terreno de juego (cancha), donde se permitía el apiñamiento de los más pobres para que apoyaran (torcieran o hincharan).

El fútbol se transformó en una industria cultural y adoptó, en la clave propuesta por Bolaño (2008), una doble función: publicidad y propaganda. La propaganda fue una estrategia usada por el Estado y los grupos políticos dominantes, quienes instrumentaron la esfera cultural del fútbol para fines ideológicos.

La función publicitaria hace referencia al uso dado por el Capital, a su condición de servir a los capitalistas individuales en competencia $y$, al mismo tiempo, a la moralidad general del capitalismo como sistema. Esta estrategia es muy cercana, a lo

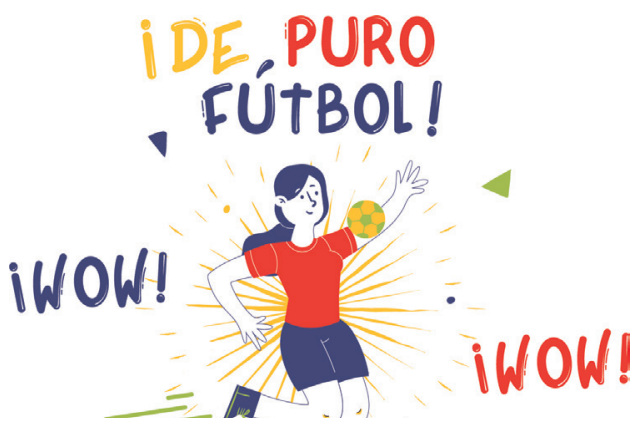

"El fútbol se transformó en una industria cultural y adoptó, en la clave propuesta por Bolaño (2008), una doble función: publicidad y propaganda." 
que Raymond Williams, llamó el "maná general" de la reputación pública del capitalismo; o sea, un recurso político de legitimación y consolidación de los valores rectores de la sociedad capitalista. En el marco de estas premisas, es que podemos entender los dos momentos que marcan el fútbol en el siglo XX. En los primeros años, el Estado se encargó de la difusión del fútbol como cultura de masas y fomentó la construcción de grandes estadios o estadios de regular tamaño en todo Brasil. En el Reino Unido, la capacidad de los estadios superaba los 80 mil asientos, como el de Wembley, construido en 1923. En Brasil, Pacaembu en 1940 y Maracanã en 1950 ejemplifican estas políticas.

En Brasil en fútbol sobresalió durante los gobiernos de Getúlio Vargas y la dictadura militar, cuando este deporte fue un medio de propaganda; la construcción de grandes estadios fue una de las principales estrategias de articulación política y búsqueda de apoyo popular. Estas obras serían fundamentales para la sostenibilidad de los clubes, ya que en esa época la taquilla era una de sus pocas fuentes de ingresos. En este contexto nacen las "generales", sectores populares que generan una cultura propia de hinchar notablemente festiva y en la que los hinchas más pobres se apilaban en emplazamientos donde no era posible observar bien el partido, pero que le otorgaban al club el estatus de "club de masas", imprescindible para atraer a otros hinchas. A estos sectores se les puede denominar "supe estadios", ya que están diseñadas para recibir la mayor cantidad posible de público. En el proceso de masificación del público en el estadio, se pueden identificar cuatro coyunturas históricas de gran importancia que caracterizan los procesos de mercantilización intensiva del fútbol. Llaman la atención porque impactan directamente en la producción del estadioconsecuentemente de su público-, ya que la función publicitaria se hipertrofia en la perspectiva reseñada arriba. 
La primera coyuntura, como observa Critcher (1979), tiene lugar en la posguerra europea, especialmente en la década de los sesenta, a partir de la configuración de la sociedad de consumo y de la competencia entre las diferentes industrias culturales y del entretenimiento. Se notará una nueva forma de gerenciar el negocio del fútbol por parte de una novel generación de líderes ligados al mundo de las empresas, influenciados en gran medida por la norteamericanización de la cultura global.

Los efectos de la mercantilización del fútbol incide sobre los jugadores, ahora famosos; sobre los hinchas, tanto los trabajadores como de los consumidores de clase media; sobre los clubes, con la conformación de un oligopolio o grupo elite de triunfadores; y sobre el juego, con un estilo más dinámico, mecanizado y pragmático; sobresaliendo el cambio de sus patrones culturales, el fútbol empezaría a ser moldeado por los dictámenes de la ganancia y quedaría inserto en la lógica de las industrias culturales o industrias del espectáculo.

La segunda coyuntura es la llegada de João Havelange a la presidencia de la FIFA en 1974, quien complejizó el negocio del fútbol, lo articuló a las grandes empresas multinacionales (globales) y encadenó su trasmisión a la tecnología satelital. Así, el valor de la boletería vendida para cada partido fue muy inferior a los ingresos percibidos por los clubes con la firma de los contratos de cesión de derechos de televisión. Estas transformaciones impactaron directamente en los estadios: el público objetivo de los clubes ya no estaba en sus ciudades de residencia, se había extendido por todo el país e inclusive por todo el mundo. De igual forma, surgieron nuevos actores económicos y se configuró una nueva relación económica entre clubes, futbolistas, hinchas de estadio y consumidores de televisión. En Brasil, el primer acuerdo televisivo importante con los clubes de fútbol fue en 1987. 
Laterceracoyunturaes la tragedia de Hillsborough (Inglaterra) en 1989. El hacinamiento en el estadio Sheffield provocó 96 muertos y cientos de heridos entre los hinchas del Liverpool. El club más popular del país y famoso por sus hooligans, fue perseguido sistemáticamente por el gobierno inglés, que ignoró las causas reales del accidente, así como la negligencia de las fuerzas policiales que hicieron poco para evitarlo ${ }^{6}$. El caso favoreció el discurso neoliberal del entonces gobierno de Margareth Thatcher, que venía intentando intervenir agresivamente el fútbol local.

Con base en el Informe Taylor, encargado de evaluar estas problemáticas, Thatcher promovió una serie de reformas de los estadios ingleses, cambios que propiciaron una nueva percepción de estos espacios y, en consecuencia, a un cambio total de su público, en línea con los elementos subrayados arriba. La conveniencia política de utilizar el tema de la violencia (real, pero sobreestimada) como fundamento para el cambio radical del público que asistía a los estadios, a través del incremento del precio de la boletería se replicaría en todo el mundo, incluso en Brasil en los años noventa y en la década del 2000. Finalmente, la cuarta coyuntura para comprender la transformación de los estadios en las últimas décadas es la exigencia, a nivel mundial, por parte de la FIFA y la UEFA a los países sedes de la Copa del Mundo y de la EUROCOPA (UEFA European Championship) de la adopción del concepto de estadios polivalentes, como condición básica para la organización de absolutamente todos y cada uno de los partidos del torneo. A partir del mundial de 1994 en Estados Unidos, estas entidades asumieron el

${ }^{6}$ En 2012, el Primer Ministro británico David Cameron, a través de una disculpa formal en nombre del Estado inglés, reconoció públicamente el fraude en los informes de accidentes, eximiendo a los aficionados del Liverpool de la responsabilidad por el mismo. 
papel de promotores internacionales de construcción de estos escenarios deportivos, que tienen altos costos de mantenimiento y fueron diseñados con el propósito de albergar diversos espectáculos de la industria del entretenimiento, como lo demuestran Cruz (2005), Mascarenhas (2013) y Simões Santos (2014).

Estos escenarios deportivos requieren por encima de cualquier otro aspecto, transformar (formatear) el público (espectadores e hinchas) del fútbol, seleccionándolo en función de sus capacidades de consumo y exigiéndole un comportamiento más pasivo y menos apasionado hacia los clubes. En definitiva, transformando al hincha en un mero consumidor. Estos aspectos conducen a la coyuntura que se presentó en Brasil, con la construcción de 14 nuevos estadios, 12 de ellos directamente relacionados con la Copa Mundial de la FIFA (2014), que creemos fue el detonante para la configuración de muchos de los nuevos movimientos de aficionados (aunque no se limiten a este tema).

\section{Resistencia de los hinchas a la comercialización}

El repentino incremento del valor de la boletería y la imposición de una serie de restricciones al carnaval (fiesta) de los hinchas en las tribunas desencadenó el rechazo por parte de las hinchadas brasileñas en los estadios y acercó a Brasil a los movimientos internacionales de hinchas. Como los procesos de circulación de ideas no son y no se crean de la nada, es conveniente reseñar brevemente dichos movimientos en el ámbito mundial, para tratar de entenderlos en el contexto global de las luchas por los derechos al estadio y al club.

En 1999, un hincha italiano de A.S. Roma publicó en Internet un documento titulado Manifiesto Contra el Fútbol Moderno. En 
cuestión de días, este manifiesto fue firmado por 72 agrupaciones (barras) de hinchas de 21 países diferentes; en resumen, en su contenido se cuestionaba la extrema mercantilización del fútbol, la distorsión de sus significados y el irrespeto a la cultura de los hinchas (NUMERATO, 2014). A finales de los años noventa, Italia era la vanguardia del fútbol internacional, los mejores jugadores del mundo vestían las camisetas de los clubes italianos. De igual forma, concentraba el mayor número de hinchadas organizadas de Ultras, subcultura integrada por grupos de naturaleza diversa, que organizaban y realizaban coreografías en las tribunas y se identificaban indistintamente con tendencias políticas, tanto de extrema izquierda como de extrema derecha?

Desde las graderías italianas -y luego alemanas, francesas, españolas, búlgaras, etc.--, estas tendencias acogieron consignas políticas y durante algunos años organizaron acciones conjuntas. Para la derecha, la crítica del fútbol moderno simbolizaba la reivindicación reaccionaria de antiguos atributos de masculinidad, virilidad, honor, tradición y nacionalismo. Para la izquierda, la lucha fue categóricamente anticapitalista, cuestionaba la elitización de los estadios y la desmedida mercantilización del fútbol.

Fueron dos caras distintas de las reacciones populares a los problemas derivados de los negocios del fútbol globalizado de los años noventa y los años dos mil; hoy en día, con la mediación de las redes sociales y con medios más ágiles y sencillos para el intercambio de información, se ha extendido por todo el mundo.

7 Según una encuesta de la Dirección General de la Policía de Prevención, organismo vinculado a la Polizia di Stato de Italia, realizada entre 2003 y 2004, el país contaba con 445 grupos activos, de los cuales se destacaron cinco tipologías: apolíticos (54\%), izquierdistas (13\%), de extrema izquierda (6\%), derechistas (16\%) y de extrema derecha (9\%). 
Algunos autores ya han analizado experiencias de resistencia de hinchadas en las cinco principales ligas europeas - Alemania, España, Francia, Inglaterra e Italia-. Los investigadores utilizaron herramientas teórico-metodológicas muy diferentes, pero con hallazgos similares. Constaron, que estas luchas no eran libradas exclusivamente por grupos de Ultras (presentes en Italia, Francia, parte de Alemania y España), sino por una amplia variedad de formas organizativas, con diferentes características, métodos y composiciones sociales. La lucha de hinchas sobresale en estos países porque ellos constituyen los escenarios de mayor desarrollo de la mercantilización del fútbol, donde la fragmentación de contradicciones y los ataques a los derechos es más evidente (SANTOS, 2015a).

En Brasil no sería diferente. Puede afirmarse que muchas de las recientes organizaciones fueron influenciadas directamente por las luchas de los hinchas europeos entre el 2000 y el 2010, difundidas a través de las redes sociales, los portales de periodismo deportivo críticos y los blogs. Es importante recordar, como señala Hollanda (2008), que en las décadas de los setentas y los ochentas del siglo pasado la lucha de los hinchas brasileños fue coyuntural, asociada con la formación de hinchadas organizadas (Torcidas organizadas) para enfrentar el autoritarismo y el mal gobierno de los dirigentes, además de cuestionar el alza en el precio de la boletería. Por tanto, es necesario distinguir estas experiencias de las surgidas recientemente, no sólo en lo que atañe al origen y composición de estas organizaciones y a las particularidades de la industrial del fútbol actualmente; sino también, de las nuevas representaciones y nuevos significados otorgados a la práctica de ser hincha.

Brasil tiene una característica única con relación a las cinco grandes ligas del mundo. Con excepción de las asociaciones alemanas, los principales clubes europeos están todos en manos de un 
socio mayoritario, multimillonarios árabes, rusos, estadounidenses, tailandeses, malayos o ingleses. Estos ajustes fueron implementados a finales del siglo XX, con base en leyes que exigían la transformación de los clubes en empresas. En cambio, los principales clubes brasileños - a pesar de los diversos ataques promovidos en los años 90- no se transformaron en compañías. Ellos protegieron su carácter de asociación civil, base fundamental de su forma de organizativa. Si, por un lado, el "conservadurismo" estatutario sólo era posible gracias al esfuerzo de los altos dirigentes para conservar el control absoluto de estas instituciones, es también la divergencia política la que permite a los hinchas exigir un mayor poder de voz y voto en los órganos de gobierno de los clubes. El fútbol brasileño se puede imaginar como una tira y afloje, en el cual los directivos son intermediarios dobles, que juegan o actúan entre la democracia para los hinchas y el autoritarismo de los mercados.

En otro momento, se identificaron e investigaron al menos siete experiencias de movimientos de hinchas que portaban pancartas defendiendo el derecho al estadio y al club (SANTOS, 2015a). Queremos ir más allá de este ejercicio descriptivo para proponer una interpretación más adecuada del proceso de internacionalización de la resistencia de los hinchas a la mercantilización el fútbol.

\section{El Derecho al estadio y al club}

En la literatura sobre la resistencia a la mercantilización del fútbol, muchos autores comparten la idea de que los hinchas creen que tienen un sentido de propiedad (sense of ownership) o afirman ser dueños simbólicos (symbolic owners) de sus clubes. Este hecho nos permite concebir el club de fútbol como un "común", en el sentido dado por Negri y Hardt (2009) a esta expresión. Para 
estos autores, lo común es producto del trabajo vivo o del vivir de las personas, una forma de trabajo no alienada en la producción capitalista; por lo tanto, posee una poderosa subjetividad y es capaz de generar conocimiento, información, afectos, relaciones sociales, etc. Lo "común" en sí mismo supera la dicotomía público-estatal/privada, configurando una forma distinta de relación colectiva con lo producido.

Para Negri y Hardt (2009) "Ios lenguajes que creamos, las prácticas sociales que establecemos, los modos de sociabilidad que definen nuestras relaciones" (p.138-14) son formas de bienes comunes culturales, entre los que se puede insertar el fútbol. Esta es una clave que permite entender el club y el estadio de fútbol como un "común" producido por la colectividad de hinchas, superando el límite del concepto capital-trabajo, que induce a pensar únicamente desde la perspectiva del futbolista.

David Harvey (2014), en diálogo con Negri y Hardt, analiza cómo se encuentran los bienes culturales comunes bajo la lógica de la mercantilización y de los "cercamientos", aspectos que define como "disneyficación". Utiliza el término para caracterizar la estandarización y adaptación de los espacios comunes a los intereses del mercado, más precisamente a la industria turística; fácilmente, se puede adaptar el concepto para estudiar el espíritu emprendedor de los clubes, el areneramiento de los estadios y el intento de transformar a los hinchas en una masa de consumidores. El club, el estadio y la cultura de la hinchada son "comunes" producidos por los hinchas y, por tanto, expropiados por el Estado y el mercado. El análisis de la expropiación de este "común", ubicado en el núcleo del fútbol, es el hilo conductor de la articulación que proponemos entre estos conceptos, como una forma de entender por qué, para qué y cómo los hinchas se organizan para resistir la 
mercantilización, proceso que los excluye del disfrute de lo que ellos mismos produjeron.

Hollanda (2008), en su investigación sobre las luchas de las hinchadas organizadas, cita la obra de E.P. Thompson (1998), para afirmar que la mayoría de las luchas en la historia estuvieron guiadas por la noción de derechos y legalidad amanezados. Con estos argumentos vincula los movimientos de resistencia de los hinchas al contexto de las luchas anticapitalistas por el derecho a la ciudad. Harvey (2014) sugiere que el descontento surge en el ciclo de circulación del capital (mercancía y dinero) y no sólo en el de la producción (trabajo), señalando que los movimientos sociales urbanos siempre tienen un contenido de clase aunque se refieran directamente a derechos, ciudadanía y reproducción social.

La cultura de los hinchas y el estadio -las formas y el templo de la hinchada- son también culturas comunes en el proceso de expropiación capitalista. Este es el punto de inflexión que se percibe en la interpretación de Gilmar Mascarenhas (2013), aunque basado en la misma matriz lefevbriana encontrada en Harvey, para actualizar la idea de derecho a la ciudad y reposicionarla para entender el estadio. Dado que el espacio social urbano es un producto inacabado del conflicto entre la lógica de la propiedad y las tácticas populares de apropiación, el estadio puede entenderse como un microcosmos de la reproducción social de la ciudad. La definición de sus condiciones de acceso y normas de uso produce conflictos y formas de negociación.

Así, el acondicionamiento de espacios polivalentes representa un momento especial de esta realidad. Primero porque con el incremento de los precios de la boletería se propicia el proceso de exclusión de los sectores menos favorecidos de la sociedad; después porque dichos procesos enseñan y limitan diversas for- 
mas y prácticas de hinchar. Por lo tanto, cuando se analizan sus repercusiones sobre la cultura del fútbol, este nuevo modelo de estadio representa una faceta del asalto neoliberal a la ciudad, porque despoja, asalta y excluye, lo que significa un retroceso en el derecho a la ciudadanía. Este argumento está muy relacionado con la idea de producción de ciudad, lo "común" y sus recientes formas de expropiación.

De este modo, las luchas emprendidas por los hinchas se enmarcan y de cierta manera reflejan la construcción de lo "común". Aunque desconocen las ideas de lo "común", estas luchas proponen su formación, construcción y defensa en el ámbito del fútbol, como una salida al agresivo proceso de mercantilización. Es así como las experiencias vividas nos hacen pensar que la lucha de los hinchas remite a dos banderas fundamentales: el derecho al estadio y el derecho al club.

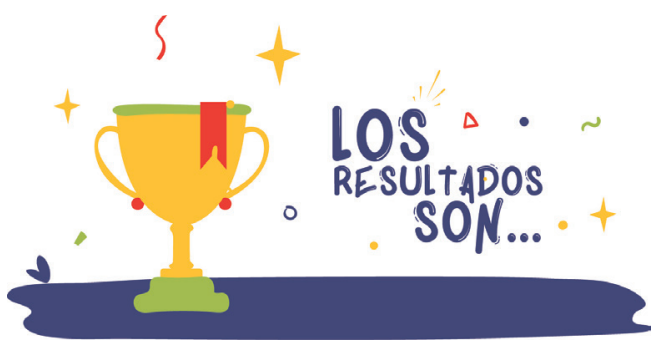

"Es así como las experiencias vividas nos hacen pensar que la lucha de los hinchas remite a dos banderas fundamentales: el derecho al estadio y el derecho al club." 


\section{Conclusión}

Como se mostró a lo largo del artículo, por medio del diálogo con varios autores, el derecho al estadio y el derecho al club se insertan en una lucha más amplia, ya consolidada, la del derecho a la ciudad. Pero hay una singularidad que sólo se puede percibir en el fútbol. Es que nadie se molestaría en liderar las políticas de federaciones deportivas como el canotaje, el atletismo o el tiro con arco, sino los atletas de estas modalidades, lo que nos lleva a creer que las cuestiones relacionadas con el fútbol están más ligadas a la vertiente cultural que a los deportes. El fútbol es un deporte singular. Es un deporte que a la vez de hacer parte del campo deportivo es una expresión cultural muy específica, que no puede situarse al mismo nivel de otras formas culturales. Pedimos permiso para incluir una cita que podría ser un epígrafe, pero que probablemente no tendría el mismo significado si se usa antes de considerar todo lo que se ha discutido hasta este punto:

De todos modos, es sólo un juego." No fue sólo un juego durante ochenta [ciento treinta] años: no desde que la clase obrera llegó a verlo como un escape del trabajo y lo reclamó como propio. No fue sólo una actividad secundaria en este siglo. Lo que sucede en el mundo del fútbol importa, no la manera en que la comida importa, sino cómo es la poesía para unos y el alcohol para otros: el fútbol expresa la personalidad. El fútbol tiene conflictos y belleza, y cuando estas dos características se unen para que el público las aprecie, representan gran parte de lo que yo entiendo por arte. La gente posee este arte de modo que nunca poseerán ninguna otra forma de música, teatro, literatura o religión, porque no puede ser engañada por el fútbol como lo es por estas cosas, donde las intenciones pueden ser deliberadamente oscuras y los métodos ocultos más allá de su alcance. (HOPCRAFT, 1971, p. 7). 
Por esta razón, hablar de justicia en el fútbol va mucho más allá de la denuncia de corrupción en la Confederación Brasileña de Fútbol (CBF) y la FIFA, como nos hacen creer los pocos y valientes periodistas críticos deportivos del país. En el caso del fútbol, las exigencias provienen de los hinchas mucho más que de los propios futbolistas (como desgraciadamente la experiencia de Bom Senso FC también hace creer).

Estos son elementos de la cultura común que están en juego. Si el derecho al estadio - es fundamental por el elevado precio de la boletería, la limitación de la fiesta al hinchar (carnaval) y la imposición de un modelo de estadio - terminó adquiriendo notoriedad con la construcción de estas arenas higiénicas y elitistas, es el momento de avanzar en una problemática, aún más urgente, el derecho al club.

Estamos hablando de la democratización de las instancias directivas de instituciones civiles centenarias que siguen siendo extremadamente limitadas y autoritarias, manteniendo a los hinchas habituales alejados de cualquier posibilidad de toma de decisiones. A pesar de avances recientes en algunos clubes, es muy difícil promover esta bandera. Es significativo, como PROFUT, la entidad federal para refinanciar las deudas de los clubes con el sindicato, exigió a los interesados en recibir su apoyo, una serie de cambios en sus estatutos, pero en ningún momento se refirió al tema de la democratización de las estructuras deliberativas y directivas de estas instituciones.

Por ejemplo, exigía que los dirigentes rindieran cuentas de arriba-abajo de los déficits presupuestarios de los clubes, sin tener en cuenta que la mayor presión para que lo hicieran recaía en los hinchas, siempre y cuando tuvieran acceso a los documentos y deliberaciones con derecho a voto. Las experiencias analizadas 
muestran que hay opciones para avanzar en el proceso. Los nuevos desafíos están relacionados con la capacidad de convocar a las fuerzas supraclubisticas y lograr el apoyo de movimientos sociales, que comprendan de una vez por todas la importancia del fútbol y los aspectos que lo rodean, su significado en la vida cotidiana de millones de habitantes de las grandes ciudades brasileñas, sean o no hinchas de algún club o, al menos, de los que asisten a los estadios.

El resultado de estas experiencias puede que no salga triunfante, pero dejaría un poderoso legado político al pueblo brasileño. O, como han empezado a vislumbrar algunos movimientos de hinchas ingleses: si todos estos esfuerzos no tienen éxito, recreemos el fútbol y nuestros clubes, volvamos a hacer todo lo que se ha hecho hasta ahora y cuidémonos de que no vuelva a ser tomado como una presa por un sistema voraz que convierte todo y a todo el mundo en mercancía. 


\section{Bibliografía}

BOLAÑO, César. (Org.). Comunicação e a crítica da economia política: perspectivas teóricas e epistemológicas. / Organizador César Bolaño - São Cristóvão: Editoria UFS, 2008.

CRUZ, Antonio. A nova economia do futebol: uma análise do processo de modernização de alguns estádios brasileiros. Rio de Janeiro: UFRJ/PPGAS, Museu Nacional, 2005.

CRITCHER, Charles. Football Since The War. In: CLARKE, J.; CRITCHER, C.;

JOHNSON R. (Orgs). Working Class Culture: Studies in history and theory. Londres: Hutchinson, 1979, p.161-184.

GIULIANOTTI, Richard. Fanáticos, seguidores, fans e flaneurs: uma taxonomia de identidades do torcedor no futebol. Revista História do Esporte, v. 5, n. 1, p. 25-46, 2012.

HARDT, Michael; NEGRI, Antonio. Commonwealth. Cambridge: Harvard University Press, 2009.

HARVEY, David. Cidades rebeldes: do direito à cidade à revolução urbana. São Paulo: Martins Fontes, 2014

HOLLANDA, Bernardo B. B. O clube como vontade e representação: o jornalismo esportivo e a formação das torcidas organizadas de futebol do Rio de Janeiro (1967-1988). 2008. 771 f. Tese (Doutorado em História) - Departamento de História, Pontifícia Universidade Católica do Rio de Janeiro, Rio de Janeiro, 2008.

MASCARENHAS, Gilmar. Um jogo decisivo, mas que não termina: a disputa pelo sentido da cidade nos estádios de futebol. Revista Cidades, v. 10, n. 17, p. 142-170, 2013. 
NUMERATO, Dino. Who Says "No to Modern Football?" Italian Supporters, Reflexivity, and NeoLiberalism. Journal of Sport and Social Issues. n. 39, n. 2, 2014, p. 120-138

SANTOS, Henrique Sena dos. "Pugnas Renhidas": futebol cultura e sociedade em Salvador. Dissertação (Mestrado em História). DCHF, Universidade Estadual de Feira de Santana. 2012.

SANTOS, Irlan Simões. "O público que devemos abolir": a elitização do futebol brasileiro e as novas Arenas. 92 f. Monografia (Graduação) - Curso de Graduação em Comunicação Social, Universidade Federal de Sergipe - UFS, São Cristóvão, SE, 2014

SANTOS, Irlan Simões. O futuro da torcida: midiatização, mercantilização do futebol e resistência torcedora. In: XXXVII Congresso Brasileiro de Ciências da Comunicação, 2015.

Rio de Janeiro, Anais do XXXVIII Congresso Brasileiro de Ciências da Comunicação. Rio de Janeiro: UFRJ, 2015a, p. 1-15.

SANTOS, Irlan Simões. Mercantilização do futebol e movimentos de resistência dos torcedores: histórico, abordagens e experiências brasileiras (no prelo), 2015b,

THOMPSON, Edward P. Costumes em comum. São Paulo: Companhia das Letras, 1998 